\title{
Inferring large-scale brain connectivity from spectral properties of the EEG
}

\author{
G Karl Steinke ${ }^{1}$ and Roberto F Galán*2
}

\author{
Address: ${ }^{1}$ Department of Biomedical Engineering, Case Western Reserve University, Cleveland, Ohio 44106, USA and ${ }^{2}$ Department of \\ Neurosciences, Case Western Reserve University, Cleveland, Ohio, 44106, USA \\ Email: Roberto F Galán* - rfgalan@case.edu \\ * Corresponding author
}

from Eighteenth Annual Computational Neuroscience Meeting: CNS*2009

Berlin, Germany. 18-23 July 2009

Published: 13 July 2009

BMC Neuroscience 2009, I0(SuppI I):P25 I doi:I0.II86/I47I-2202-I0-SI-P25 I

This abstract is available from: http://www.biomedcentral.com/I47I-2202/I0/SI/P25 I

(C) 2009 Steinke and Galán; licensee BioMed Central Ltd.

\section{Introduction}

Study of recorded electroencephalogram (EEG) data has demonstrated that the brain exhibits global dynamics with specific spectral properties [1]. In particular, it is noted that large-scale brain activity consists of the superposition of background "pink noise" and a number of specific frequency bands whose spacing reduces the potential for cross-talk (band peaks are evenly spaced on a logarithmic scale). The relationship between network topology and observed activity is a topic of ongoing research, but it has been observed anatomically that largescale connectivity in the brain is nonrandom, displaying a small-world topology [2]. This topology maximizes the complexity of the brain dynamics, allowing for a large repertoire of physiologically relevant activity patterns. Thus, it is desirable to infer details regarding the connectivity of a neural network based on observation of its dynamics.

\section{Methods}

Using a stochastic dynamical model of large-scale brain activity $[2,3]$, we found a relationship between the power spectrum of EEG traces and the eigenvalues of the connectivity matrix. Because many different matrices have the same set of eigenvalues, the EEG spectrum alone is not sufficient to determine the underlying network connectivity. We thus impose one constraint: the connectivity matrix must have a small-world network topology. We then solve the inverse-eigenvalue problem [4], obtaining a family of connectivity matrices compatible with this condition, that in the simulations generate EEG with the power spectrum experimentally observed.

\section{Results}

The reconstructed connectivity matrices display globally balanced excitation and inhibition (positive and negative entries, respectively) as well as the presence of hubs, which are characteristic of small-world networks (Figure 1).

\section{Acknowledgements}

This work has been supported by The Mount Sinai Health Care Foundation.

\section{References}

I. Buzsaki G: Rhythms of the Brain First edition. Oxford University Press; 2006.

2. Sporns O, Tononi G, Edelman GM: Theoretical neuroanatomy: relating anatomical and functional connectivity in graphs and cortical connection matrices. Cereb Cortex 2000, I0:|27-|4|.

3. Galán RF: On how network architecture determines the dominant patterns of spontaneous neural activity. PLOS ONE 2008, 3:e2I 48.

4. Chu MT, Golub GH: Inverse Eigenvalue Problems: Theory, Algorithms, and Applications Oxford University Press; 2005. 

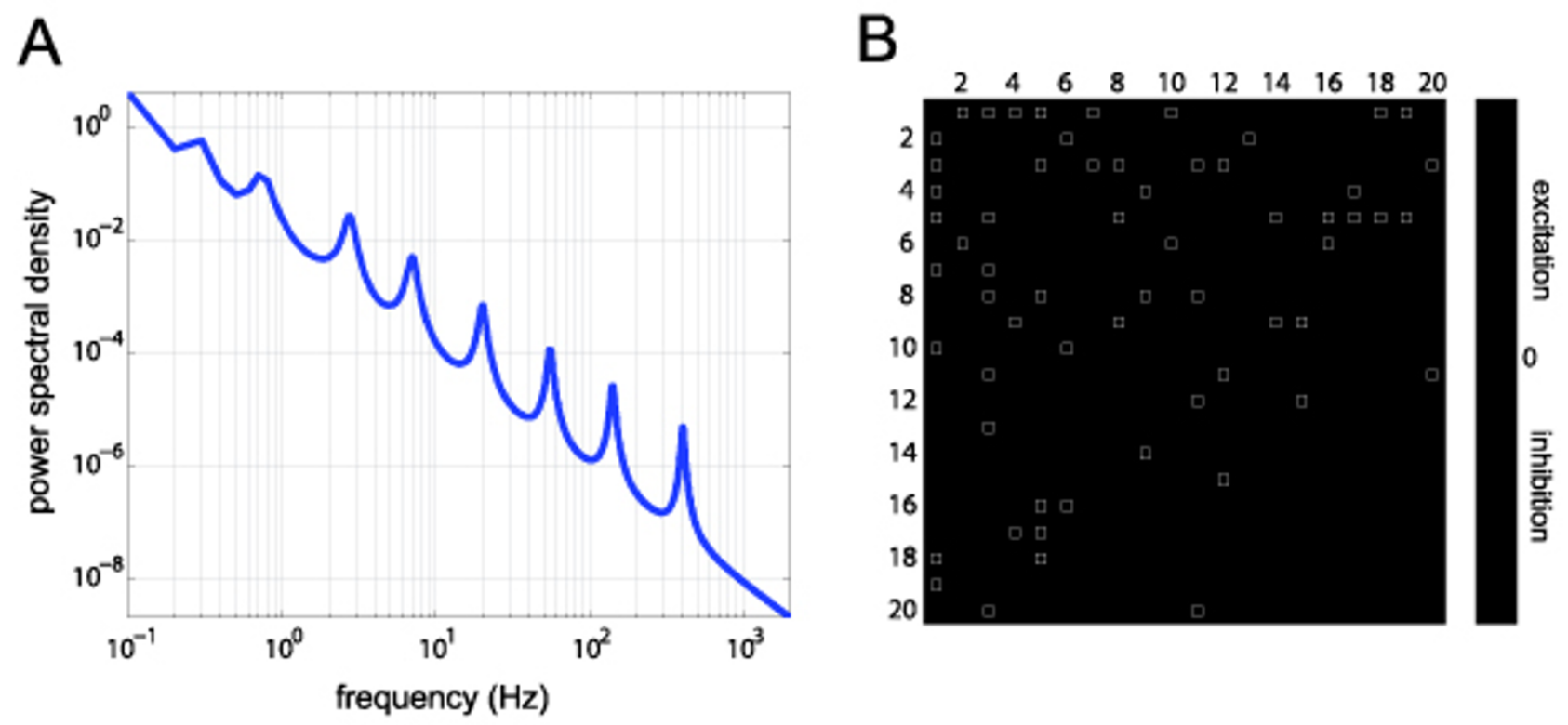

\section{Figure I}

Connectivity matrix reconstructed from the EEG power spectrum. A: Simulated power spectrum of EEG traces. B: Connectivity matrix that leads to an EEG with the same power spectrum as in A. Black squares represent the underlying smallworld network topology.

Publish with Bio Med Central and every scientist can read your work free of charge

"BioMed Central will be the most significant development for disseminating the results of biomedical research in our lifetime. "

Sir Paul Nurse, Cancer Research UK

Your research papers will be:

- available free of charge to the entire biomedical community

- peer reviewed and published immediately upon acceptance

- cited in PubMed and archived on PubMed Central

- yours - you keep the copyright
BioMedcentral 